This item was submitted to Loughborough's Research Repository by the author.

Items in Figshare are protected by copyright, with all rights reserved, unless otherwise indicated.

\title{
The market development of avaition biofuel: drivers and constraints
}

PLEASE CITE THE PUBLISHED VERSION

http://dx.doi.org/10.1016/j.jairtraman.2014.03.003

PUBLISHER

(c) Elsevier

VERSION

AM (Accepted Manuscript)

LICENCE

CC BY-NC-ND 4.0

REPOSITORY RECORD

Gegg, Per K., Lucy C.S. Budd, and Stephen G. Ison. 2014. "The Market Development of Avaition Biofuel: Drivers and Constraints". figshare. https://hdl.handle.net/2134/14481. 
This item was submitted to Loughborough's Institutional Repository (https://dspace.lboro.ac.uk/) by the author and is made available under the following Creative Commons Licence conditions.

\section{creative
commons}

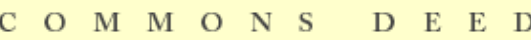

Attribution-NonCommercial-NoDerivs 2.5

You are free:

- to copy, distribute, display, and perform the work

Under the following conditions:

Attribution. You must attribute the work in the manner specified b the author or licensor.

Noncommercial. You may not use this work for commercial purposes.

No Derivative Works. You may not alter, transform, or build upon this work.

- For any reuse or distribution, you must make clear to others the license terms of this work.

- Any of these conditions can be waived if you get permission from the copyright holder.

Your fair use and other rights are in no way affected by the above.

This is a human-readable summary of the Leqal Code (the full license).

\section{Disclaimer 만}

For the full text of this licence, please go to: http://creativecommons.org/licenses/by-nc-nd/2.5/ 


\title{
The market development of aviation biofuel: drivers and constraints.
}

\begin{abstract}
Aviation biofuel is technically viable and nearing the commercial stage. In the last ten years, biofuels have moved from relative obscurity to a point where certain types of fuel have become fully certified for commercial use in up to $50 \%$ blends with standard jet fuel and commercial partnerships between airlines and biofuel producers are being established. Yet despite numerous successful test flights, aviation biofuels have yet to become widely commercialised. Drawing on the findings of in-depth interviews with leading global aviation biofuel stakeholders undertaken between October and December 2011, this paper identifies and examines the perceived factors that are affecting the market development of biofuels for aviation. The paper illustrates that market development is being driven by the combined effects of rising jet fuel prices, the potential future impact of emissions legislation and concerns about fuel (in)security. However, commercialisation is being constrained by high production costs, limited availability of suitable feedstocks, uncertainty surrounding the definition of the sustainability criteria, and a perceived lack of both national and international political and policy support for aviation biofuel. The implications of these findings for commercial aviation and the future development of global market for aviation biofuel market are discussed.
\end{abstract}

\section{INTRODUCTION}

The need to develop commercially viable alternatives to traditional fossil-based liquid fuels for commercial aircraft is intensifying. The rising price of crude oil, potential new carbon emissions legislation, the negative environmental externality effects resulting from fossil fuel consumption (including, but not limited to, atmospheric pollution and anthropogenic climate change), and growing global demand for air travel have collectively motivated research into sustainable fuel alternatives (Köhler et al, 2014; Nair et al, 2014). Liquid biofuels are at the forefront of these developments as they have the potential to confer significant economic and environmental benefits and can be 'dropped in' to existing infrastructure. Worldwide, research and development into new types of alternative fuel has grown significantly during the last 10-20 years as a result of the use of mandates, tax breaks, subsidies and advantageous funding arrangements between biofuel producers and national governments (Panoutsou et al, 2013). This has resulted in commercial markets for liquid biofuels being established in Europe, North America, South America, Asia, Asia Pacific and Africa (Köhler et al, 2014).

Until recently, biofuels were predominantly used by the road transport sector as direct and more environmentally friendly substitutes for conventional petrol and diesel (see Freedman, 2014). Although the rail and maritime sectors have also begun to experiment with biofuels as a way to reduce the carbon intensity of their operations (Florentinus et al, 2012), some of the most dramatic developments have occurred within the commercial aviation sector. The aviation industry faces a unique and increasingly acute set of environmental and energy challenges and many airlines are currently pursuing biofuels as a means to reduce their oil dependency, lower their greenhouse gas emissions and improve their environmental performance. As the unprecedented high price of oil of \$147USD a barrel in 2008 demonstrated, the air transport industry is particularly vulnerable to rising and volatile oil prices. Fuel constitutes a major component of an airline's operating cost. In the last 10 years, fuel costs have doubled to account for 28\% of airline operating expenses in 2013 (PWC, 2013). As a result of the high oil price, a number of airlines worldwide were forced to declare bankruptcy during 2008 and hundreds of thousands of passengers had their travel plans disrupted (Mazraati, 2010). In addition to fuel price concerns, the air transport industry is also under increasing public and political pressure to address its environmental impacts (see Bows-Larkin and Anderson, 2013). In response, the industry is making a concerted effort to reduce greenhouse gas emissions (particularly of carbon dioxide) by investing in more fuel 
efficient technologies and environmentally friendly operating practices (Budd and Budd, 2013) as well as in alternative fuels sources to reduce emissions (Winchester et al, 2013a).

IATA has set a target for the global aviation industry to achieve carbon neutral growth by 2020 and reduce CO2 emissions by 50\% relative to 2005 levels by 2050 (IATA, 2009). In the US the Federal Aviation Administration (FAA) aims for 1 billion gallons of jet fuel to come from alternative renewable sources from 2018, representing $1.7 \%$ of predicted fuel consumption of US carriers (FAA, 2011, Winchester et al, 2013b). Moreover, alternative jet fuels can both qualify under the Renewable Fuels Standard in the US, and under the EU Renewable Energy Directive, although there is no specific mandate for jet fuel. Crucially, the industry has few short-term technological options at its disposal which would confer the required emissions reductions while simultaneously reducing oil dependency and protecting growth (Blakey et al 2011; CCC, 2009). While some efficiency gains can be delivered through fleet renewal and enhanced air traffic management procedures such as continuous decent approaches and precision area navigation (P-RNAV) these measures will not, by themselves, be sufficient to deliver the drastic reductions in emissions which are required and additional interventions are required. At present, virtually all of the world's commercial aircraft are powered by engines that burn Jet A/A1 fuel and produce a range of pollution species as by-products of combustion and incomplete combustion. Although alternative propulsion technologies, such as hydrogen fuel cells and solar power, have been proposed and subjected to a degree of testing, and they are not yet certified for commercial use. Liquified natural gas has also been produced as a future aviation fuel since it offers lower fuel burn and emissions and potential cost and availability benefits (Stephenson 2012). One of the most attractive short-to-medium term options for the air transport industry is, however, to continue to operate existing engines and aircraft but use lower carbon fuels. As this will show, although certification for 50\% blends of FT biofuels achieved in 2009 and HEFA fuels in 2011, many challenges to widespread commercialisation remain (IATA 2013). The paper begins by reviewing the current state of aviation biofuel testing and research worldwide. This is followed by a description of the data collection method that was employed, an examination of the key findings, and a discussion surrounding their implications for commercial aviation and the continued development of aviation biofuels.

\section{DEVELOPMENTS IN AVIATION BIOFUEL}

The term biofuel refers to any form of renewable energy that is derived from biomass.

Biofuels can be solid (e.g. wood), liquid or gas and can be produced from an array of feedstocks, wastes and production processes. There are two basic forms; primary biofuel and secondary biofuel. Primary biofuels, such as wood chippings and agricultural waste, are the most basic form of bioenergy and require no additional processing (see Naik et al, 2010). Secondary biofuels are made from biomass that has been processed to change its chemical composition. These processes include fermenting sugar crops to produce ethanol, pressing oil rich crops to produce vegetable oil, superheating biomass to create combustible gas and combining different types of liquid or gaseous biofuel together.

However, in order to produce biofuels that have the required chemical and flow characteristics for use in aircraft engines, advanced processing techniques have need to be developed (see Chuck and Donnelly, 2014). The main processes of producing aviation biofuel involve either hydrotreating vegetable oils to make hydrotreated renewable (HEFA) fuels or performing gasification of biomass feedstocks using the Fischer-Tropsch process (FT) (CCC, 2009). Both techniques produce a bio-derived paraffinic hydrocarbon known as Bio-SPK. Crucially, the resulting bio-SPK not only has similar chemical properties and comparable flow characteristics at low temperatures to standard commercial Jet A/A1 fuel but it also does not contain Fatty Acid Methyl Esters (FAME), water, metal particles or other contaminants. To ensure the safety and performance of Bio-SPK fuels, a lengthy period of testing commenced. Trials on commercial aircraft followed from 2008 onwards and involved different airframe and engine combinations as well as a variety of different feedstocks and blend ratios.

As a result of extensive trials, ASTM (formerly known as the American Society for 
Testing and Materials, a global leader in the development of international voluntary standards) certification for BtL and HEFA fuels was granted for commercial purposes in up to $50 \%$ blends in 2009 and 2011 respectively (ASTM, 2011). The 50\% blend limit was established to guarantee the presence of 'aromatics' in the fuel which are essential for the effective operation of engine fuel seals but which are not present in biofuels (Corporan et al, 2011). With ASTM certification achieved, major airlines began to source biofuels and operate scheduled commercial flights powered, in part, by biofuels. KLM operated one of the first revenue biofuel flights in July 2011 when it flew 171 passengers from Amsterdam to Paris in a Boeing 737 part-powered by biofuel derived from waste cooking oil (KLM, 2012). Later that year, Lufthansa conducted a six month trial using biofuel derived from a variety of plant and animal fats to power 1,187 flights between Hamburg and Frankfurt (Lufthansa, 2012).

Although all of these trials involved short term co-operation between airlines, airframe and engine manufactures, airports and biofuels suppliers, one of the main challenges airlines faced was sourcing sufficient supplies of biofuel. To overcome this challenge and reduce vulnerabilities in the supply chain, airlines and biofuel producers began establishing commercial partnerships. British Airways agreed to co-fund, with US firm Solena, the development of the UK's first commercial scale waste-to-liquid aviation biofuel facility in east London which aims to convert 500,000 tonnes of domestic refuse into 50,000 tonnes of aviation biofuel a year (British Airways, 2013) while Virgin Atlantic entered into a partnership with Swedish biofuel company Lanza Tech (Enviro.aero, 2012). In June 2013 it was announced that United Airlines will purchase 15 million gallons of renewable jet fuel over a 3 year period (Lane 2013). However, despite these (and other) commercial partnerships, barriers to market development remain. This paper reports on the findings of a series of in-depth interviews with major aviation biofuel stakeholders worldwide.

\section{METHOD}

25 aviation biofuel stakeholders based in Europe and North America were identified from extensive literature and internet searches (Table 1). Respondents were drawn from sectors including airframe manufacturers, airlines, environmental consultants and (bio)fuel companies. Initial contact was made via email and interviews, which averaged one hour in length, were conducted by telephone between October and December 2011. Whilst recognising the methodological limitations of the research undertaken, not least in terms of the limited sample of the stakeholders interviewed, the research presented here contributes to extant debates on the future commercial development of aviation biofuel by examining the perceptions of fuel producers, end users and policy makers.

The semi- structured interview schedule consisted of open-ended questions relating to four key areas that had been identified from the literature as representing gaps in the existing knowledge base. These areas were: the historical development of aviation biofuels, contemporary challenges facing commercialisation, stakeholders' views on policy and legislative support, and areas requiring further research. All of the interviews were recorded on a dicta-phone, transcribed and coded by the lead author. Anonymity was granted to safeguard personal privacy and to conform to the respondent organisation's confidentiality agreements. Consequently, individual respondents are identified by a letter and their generic job description.

\section{TABLE 1 List of Respondents}

\section{Respondent Sector}

A

B

C
Airframe Manufacturer

Airframe Manufacturer

Airline
Job Description

Senior VP of Environment

Biofuel Public Relations Officer

Environment Manager 


$\begin{array}{lll}\text { D } & \text { Airline } & \text { Environment Director } \\ \text { E } & \text { Airline } & \text { Environment Manager } \\ \text { F } & \text { Airline } & \text { Environment Manager } \\ \text { G } & \text { Airline } & \text { Environment Manager } \\ \text { H } & \text { Airline } & \text { Bioenergy and biofuels research } \\ \text { I } & \text { Airport operator } & \text { Operations Director } \\ \text { J } & \text { Aviation biofuel producer } & \text { Director of Corporate Affairs } \\ \text { K } & \text { Aviation biofuel producer } & \text { Strategy Director } \\ \text { L } & \text { Biofuel agency } & \text { Biofuel Expert } \\ \text { M } & \text { Engine Manufacturer } & \text { Director } \\ \text { N } & \text { Environmental Consultancy } & \text { Consultant } \\ \text { O } & \text { Environmental Consultancy } & \text { Consultant } \\ \text { P } & \text { Environmental Consultancy } & \text { Director } \\ \text { Q } & \text { Fuel standards agency } & \text { Manager } \\ \text { R } & \text { International aviation body } & \text { Deputy Director } \\ \text { S } & \text { Petrochemical company } & \text { Biofuel Expert } \\ \text { T } & \text { Petrochemical company } & \text { Biofuel Expert } \\ \text { U } & \text { Petrochemical company } & \text { Biofuel Manager } \\ \text { V } & \text { Renewable Energy Assoc } & \text { Policy Advisor } \\ \text { W } & \text { UK Government } & \text { Aviation Analyst } \\ \text { X } & \text { University academic } & \text { Professor Energy } \\ \text { Y } & \text { US Government } & \text { Aviation Analyst }\end{array}$

\section{FINDINGS}

The findings are organised under the headings of drivers and constraints. The section begins by highlighting the complexity and interdependency of key factors driving the development of aviation biofuels, followed by a discussion of the issues which are constraining the widespread commercial uptake and continued market development of aviation biofuels.

\section{Drivers}

The interviews identified six key drivers supporting the development and uptake of aviation biofuels. These drivers were either external economic factors (including high jet fuel prices and energy prices) or potential benefits associated with the fuels' eventual uptake (including job creation and economic growth). Although there is a high level of interdependency between individual factors, the single most important factor identified was the need to reduce carbon emissions. 


\section{Carbon reduction}

All 25 respondents stated that the aviation industry needed to reduce its carbon emissions. This stems in part from political and public pressure as well as more stringent environmental targets. Although there was a general consensus among all respondents that carbon emissions were a significant driver, there were subtle differences between EU and US respondents. EU based respondents; which represented around two thirds of the interviewees, suggested that reducing emissions was motivated by environmental legislation and voluntary industry targets. Non-EU respondents acknowledged the role played by environmental legislation, but suggested that other factors were also important. Interestingly, national environmental legislation within the US was deemed to be insignificant. US respondents were also much more open to discussing the threat that environmental legislation had for 'raising costs' rather than achieving a reduction in emissions. In fact, most non-EU respondents stated that the extra cost associated with carbon reductions was the primary driver for biofuels, not necessarily the emission reductions themselves. Airline D stated:

"Environmental legislation will increase our costs. This is the bottom line when we think about reducing emissions, and I know a lot of other airlines think exactly the same."

This view was shared by the majority of US respondents. This is not to say that EU respondents were unaware of the cost implications associated with reducing emissions since they appeared to be consciously factoring it into their future business strategies. EU airlines were also aware of the long term implications of carbon pricing on profitability, but many had recognised there was potential to raise valuable revenue by reducing their emissions and selling permits that were surplus to requirements. According to Airline E, emissions reductions will play a larger role in the EU airline industry's business strategy in future years:

"Strategically we knew that emissions are a key issue to get right. We are looking therefore for long term solutions. We are not sure that biofuels will be the sole measure used but they will definitely be part of the mix."

In addition to the EU ETS, voluntary emission targets provide a strong motivation for EU airlines, engine and aircraft manufacturers to reduce their carbon emissions. One European airframe manufacturer focused on their own industry targets, asserting they are the most important driver in terms of aviation biofuels:

"Aviation is one of the few industries that have clear targets for reducing $\mathrm{CO}_{2}$. [We want] carbon neutral growth by 2020 and 50\% $\mathrm{CO}_{2}$ reduction by 2050. That"s a key target we have all committed to, along with all other airlines and manufacturers ... So this is the primary driver" [Airframe manufacturer A].

Industry led initiatives were also identified by Airline F as being important.

"The aviation industry is driving this more than anything else; more than investors, more than governments; even more than the fuel industry."

Despite there being a number of economic sectors involved in the development of aviation biofuels, around half of respondents agreed that the aviation industry is playing a leading role in developing aviation biofuels. It is doing this in three main ways. First, through initiatives such as the Sustainable Aviation Fuel Users Group (SAFUG) and the Commercial Aviation Alternative Fuels Initiative (CAAFI) which seek to encourage dialogue between stakeholders 
and governments, as well as encourage investment in the technology. The second is through airline producer partnerships; where certain airlines are planning to produce their own fuel by forming a co-funding agreement with biofuel producers; such as in the case of British Airways and Solena. Finally, by forming consortia of airlines, biofuel producers and feedstock growers that can streamline the development stages of new fuels and create sustainable supply chains. The importance of aviation led initiatives has strengthened considerably since the certification of BtL and HEFA biofuels in 2009 and 2011 respectively.

According to twelve respondents, the development of consortia created high profile interest in the fuel from investors, airlines and producers. Although the support is still limited, these initiatives appear to be creating a positive signal relating to the benefit of the fuel. Respondents stated that the predominant work that had been carried out had been organised by the aviation industry i.e. airlines, engine manufacturers and airframe manufactures. Indeed, Boeing and Airbus were cited as being particularly supportive of aviation biofuel development. One of the main reasons for this was the perceived lack of involvement of major oil companies.

"We were waiting for the big oil companies to come in and help us. However, I think what emerged was a fairly consistent feeling across the airline industry that we can"t wait for big oil companies, so there are a number of airlines now that are getting involved in the manufacture of the fuels themselves. " [Airline C]

Further evidence suggests that the airlines had a pioneering role in driving the initial interest in the fuel. Five respondents, all of which offer services to airlines, acknowledged that their initial interest in the fuel only came about after the airline industry approached them regarding advice or services. For example, one aviation biofuel producer stated that their initial venture into aviation fuels only came about after it was made apparent that a niche market existed for the fuels.

"...we already designed the technology so we had the possibility to also provide jet fuel, but we saw the road sector as the main user. The [aviation] market came to us.... they came to us pretty quickly after we announced our production capacity." [Biofuel Producer J]

\section{Energy security}

The issue of energy security was raised by all 25 respondents as a potential driver of aviation biofuels. It was acknowledged as being the most significant by U.S and Brazilian respondents. The U.S respondents spoke about the energy security benefits of the fuel and the ability to avoid oil imports. Energy security was also acknowledged to act as a major driver within the U.S from a military perspective. Four respondents acknowledged that military demand for aviation biofuels within the U.S. may act as a catalyst for both the development and eventual uptake of the fuels in the commercial sector:

"From the military side, military customers are interested in the commercialisation of biofuels from a supply assurance perceptive, so fuel supply security. They don " $t$ want their fuel supply disturbed in the future." [Engine Manufacturer $\mathrm{M}$ ]

Outside the U.S. securing energy supplies is attractive to governments both from an economic and a commercial perspective. Airframe manufacturer B acknowledged that the energy security benefit aviation biofuel could confer represents a significant benefit for national governments and policy makers. Reducing oil imports furthermore benefits national economies by creating additional labour demand for the production of domestic biofuel. 
Despite the advantages, most respondents saw energy security as more of a long-term benefit that would manifest itself in ten to twenty years' time. Issues of oil supply and security were reflected in the discussion about oil prices and price volatility which were recognised as constituting another important driver.

\section{Volatile oil prices}

Oil price rises and oil price volatility were identified as long term drivers by almost all of the respondents. Some respondents mentioned that the initial interest in biofuels followed the 2008 price spike, but this was denied by others. Oil prices were normally mentioned as a long-term driver in connection with carbon price rises. Indeed, the combined effect of oil price rises and carbon legislation was often cited as creating an important driving force. It was also suggested that oil price volatility will play a larger role than oil price in the shortterm and long-term according to a quarter of the respondents. One possible explanation was expressed by an EU airline respondent. The airline stated that aviation biofuel producers will seek to match the price of jet kerosene, minus whatever carbon price is attached to the fuel in the future. This means that there will be no spot price incentive for using aviation biofuel compared to kerosene. The incentive instead comes from the fact that aviation biofuels may be more price stable.

\section{Legislation}

A significant number of respondents mentioned legislation as an important driver with mention made of the EU ETS and the ICAO resolution. The EU Emissions Trading System was by far the most discussed legislative driver. In total, twenty respondents mentioned the EU ETS as an important driver for aviation biofuel, either in combination with other drivers or exclusively. Most respondents stated that the legislation is predominantly a long-term driver because the price of carbon is currently too low. The EU ETS was described in two main ways: either a threat to the profitability of the aviation sector and/or as an opportunity to reduce the aviation industry's emissions. EU respondents tended to cite the environmental benefits of the system, whereas U.S respondents tended to cite the financial burden it will impose. All respondents however understood that the EU ETS will fundamentally affect the industry. Airport I stated:

"Emissions are going to start costing airlines money because of increased costs of carbon. I know for a fact that some airlines don"t think about the EU ETS as an environmental issue, they think about the extra costs"

In contrast to EU airlines, North American respondents stated that US airlines are not subjected to significant environmental legislation nationally, and the main threat was perceived to be almost exclusively the EU ETS. Non-EU respondents also generally discussed their concerns about the possible introduction of an emissions trading system in other world markets. For example one major U.S. Engine manufacturer stated:

"...there is no domestic policy for reducing emissions that is being worked currently...but, the airlines are very worried about a spread of an ETS system globally that will increase the price of fuel..."

The second legislative measure mentioned were subsides for aviation biofuels. Three respondents mentioned the way the Dutch government had interpreted the renewable Fuel Directive was a potentially useful development. One respondent mentioned that is was an important driver locally for the industry, but not significant on a global scale. The third legislative driver related to ICAO's recent environmental resolution. One academic stated that ICAO had recently created a resolution that states that every member country must provide an action plan outlining the ways they intend to reduce aviation emissions. The UK academic spoke at length about how this is a positive move towards creating a global policy with respect to emission reductions. The respondent mentioned that up until now, ICAO's influence on 
environmental matters had been lacking and this is a significant indication that ICAO may begin ensuring countries are using appropriate measures to reduce emissions.

"This year it was for the "first" time that a resolution on the environment was made. So now every country must send an action plan for climate reduction to ICAO for them to review. This is a good start." [University academic, $\mathrm{X}$ ]

\section{Lack of alternative technology}

Ten respondents acknowledged that the aviation industry has a lack of alternative technologies to de-carbonise. Respondents stated that the aviation industry has a serious long term issue in that it does not have many replacement technologies that offer the same performance as the jet-airliner. It was stressed very clearly by two engine manufacturers and three airframe manufacturers that the industry needs to either diversify its propulsion technology or use a replacement low carbon fuel; with the latter being the most viable option. Although efficiency improvements are still the research focus for those companies, the longterm future of the industry points towards radical technologies such as biofuels which offer a step change in emissions. Other respondents expressed the same opinion by comparing the aviation industry to other transport sectors such as road and rail which have considerably better options for reducing emissions. Academic X stated:

"...if you look at the car industry they have several sources of emission reductions. Aviation does not. They can "t rely on one type of fuel. For this reason biofuel is a potential solution"

Other respondents added that the only cost effective solution for the next 40 years will be to use aviation biofuels. The other technologies which are being looked at such as hydrogen and electric are too far away from feasibility and cost effectiveness. Aviation biofuels were therefore seen as an 'essential' intervention.

\section{New business opportunities}

Aviation biofuels create new business opportunities, although at present the economics of the fuel were still seen as undesirable and it will take several years before the fuel becomes economically viable. Nonetheless, the technology was championed by certain individuals with one airline stating that although the costs involved with producing the fuels today are high, in the long-run there is a clear economic case to support biofuels.

\section{"We might lose money in the short term but in the long term the benefits are very large, we believe.”[Airline E]}

The academic respondent was also confident that the technology had clear economic advantages in the long-run, referring to their experience in researching the economics of the fuel in Europe. Other respondents described the need to support the technologies in their early stages in order to scale up production and reap greater benefits of economies of scale from the technology later. For example Airline F stated: 
"...it takes a long time. But if we start the work now it will pay dividends in the future. First you've got to get the process right, and then you've got to get the network together for the raw product."

At present however the production volumes of the fuel remain small. Indeed, it appears that although the business opportunity that aviation biofuel presents is apparent considerably more effort and investment will be required to scale up production.

\section{Constraints}

Respondents acknowledged a number of constraints associated with the market development of aviation biofuels with the constraints often closely interlinked.

\section{High Production Costs}

High costs were mentioned by all respondents as a significant constraint to the development and uptake of aviation biofuels. All respondents acknowledged that the purchase price of aviation biofuels given current technology will be higher than the price of standard jet fuel. Biofuel producer K stated:

"The price of bio-kerosene is at least twice the price of fossil jet fuel alone. And the price is really a challenge. We are working hard to get the costs down but this is a major issue for everybody."

Estimates for price parity were given reluctantly, but most estimates were between 2015 and 2030. This large variation may be explained, in part, by the complexity of the cost issue. When respondents elaborated on the cost issue it was apparent that estimating the final cost of aviation biofuels can be difficult since the final price can be influenced by various factors such as: the production process, feedstock costs, the cost of infrastructure and legislative support. Each of these components will vary depending on the technology being used, the region, and the level of infrastructure available and legislative support.

\section{Lack of investment}

$80 \%$ of the respondents acknowledged that aviation biofuel technology was receiving insufficient investment. Most of these respondents believed that the main factors hindering the level of investment were: uncertainty about the technologies and legislative support and an inability to obtain credit given the global economic downturn. Further factors included an inability to de-risk investments and a lack of government investment. In terms of investment Airline C stated that:

"We had a hard time getting finance. Banks don't want to take a risk on a "first of a kind technology". Apart from the US, the UK hasn't got their heads around how they will de-risk these investments. The US on the other hand is doing much more than the EU."

When the airline mentioned de-risking, they were referring to the presence of government backed loans or guarantees that can be offered to insure against losses on the technology. Indeed, with the exception of the US, there are very few regions where 'derisking' is occurring according to the respondents.

The other constraint relating to investment was acknowledged as a lack of government grant funds for new biofuel technologies and the way government funds are administered. Four respondents mentioned that the way grant funding is administered may be 
suppressing promising technologies before they have a chance to show their potential. The main issue being that funding is not being given out quickly enough. One respondent spoke passionately about the fact that very often in Australia and Europe the time required to administer funds could be up to a year. According to the respondent, in that time the company can easily go bankrupt. Referring to the Australian funding system specifically, respondent $\mathrm{V}$ stated:

"In almost all of cases, the political nature of the funding means that the time frames to allocate the funding are too long, if you have a start-up company that needs cash, 18 months is a ludicrous amount of time to wait - and it happens elsewhere. There is a need for quicker decision making."

\section{Sustainable feedstock supply}

A lack of sustainable feedstock supply is seen as an important constraint according to all the respondents. Respondents commonly described the aviation biofuel industry as being 'lacking in sufficient feedstocks to make existing technologies economically viable and sustainable'. The emphasis moreover was on a lack of 'sustainable feedstocks' which meet both economic and environmental criteria. The main reasons for a lack of sustainable feedstock supply that were acknowledged to include: the lack of a supply chain, feedstock research and a clear sustainability criteria.

A lack of supply chain was mentioned by ten respondents. Five respondents from the CAAFI initiative called this the 'agricultural vertical'. Respondents stated that at current levels, the agricultural vertical for sustainable feedstocks is almost non-existent in most regions. This means that the physical and monetary effort to obtain sustainable feedstocks is excessive. Respondents that had been involved in creating a supply chain for aviation biofuels in Brazil described the work required to source relatively small amounts of sustainable Jatropha feedstock as 'excessive and 'non-economic'. The respondents described a situation in which the final feedstock delivery for a particular trial was amalgamated from numerous geographically scattered batches.

"...for one of the trials we sourced the Jatropha nuts ourselves. It was a big challenge because we had to squeeze every little bit we could find from all over the country just to get enough and there was no supply chain yet so the logistics were also a challenge." [Airline D]

The second issue acknowledged was a lack of feedstock research. Although major breakthroughs have been made surrounding new feedstocks and production methods, there is still a considerable amount of research required. One respondent stated that all too often attention is focused on the production side of the business i.e. on the processing technology, rather than on the feedstock bases. This was described as being highly counterproductive. The respondent elaborated on the views of other respondents in saying that more research effort and funding is required on the feedstock side to ensure that the processing technologies have sufficient raw materials to produce fuel. Respondent V stated:

"There's a tendency we focus on the production side of things because that is the attractive and interesting side of the business, whereas in reality there is so much work to be done on the feedstock side. The reality is that the plant you build once, while the biomass will be used for 30 or 40 years."

Related to a lack of feedstock research is a lack of sustainability criteria for aviation biofuel feedstocks. This was expressed by the same ten respondents from mixed sectors. Although 
there are various projects underway to tackle this issue, at present it is hindering the development of the industry. As well as creating uncertainty for investors, one respondent stated how farmers are not getting sufficient information about sustainability criteria. One US airline respondent described this sentiment for some U.S farmers. Related to sustainability of feedstocks are the environmental effects of land use change and pressure on the food supply.

\section{Inadequate legislation}

Lack of legislation was a constraint which almost all of the respondents described as being a serious issue. Most respondents described this issue as a 'lack of level playing field' between road-based biofuels and aviation biofuels. Others discussed a lack of legislation more generally with respect to insufficient funding or supportive measures for the fuels.

The focus of many stakeholders was on the EU which, with the exception of the Netherlands, favoured the use of road based biofuels over aviation biofuels in its use of legislation. Road based biofuels were described as being supported by a plethora of incentives and legislative support measures including: subsidies of feedstocks, mandates of biofuel blending and tax breaks. This was described as being 'unfair' for aviation biofuels.

Another common topic of discussion surrounding legislation was the EU ETS. Almost all of the respondents stated that that although the system has a zero carbon accounting procedure for aviation biofuels, this does not create any incentive to use aviation biofuels. This is because the price of carbon is too low.

An additional issue relating to legislation was the level of knowledge flows between legislators and the aviation biofuel community. The main area of focus related to the EU. It was expressed by over half of the EU respondents that there is inadequate knowledge flows between legislators and the industry, and this may be impacting on the industry's ability to develop. Airline $\mathrm{C}$ described their interaction with legislators as follows:

"We do try to talk a lot to legislators and make recommendation but there are so many issues to resolve. It's not all that encouraging that they are taking it all in from what we see."

In addition to the constraints above there were other issues which were mentioned by a few respondents. These include: applying too strict environmental criteria on aviation biofuels and a pipe-line infrastructure certification issue.

\section{Strict environmental controls for biofuels}

The issue of having strict environmental hurdles for aviation biofuels was flagged up as being a potentially overlooked constraint by three respondents. The issue surrounds the idea that legislators and NGO's are being too strict on setting environmental hurdles for aviation biofuels. Despite the fact that there are no formal environmental guidelines for aviation biofuels as yet, the respondents warned that the initial interest is too focused on overly optimistic technologies. The respondents explained that there may be a tendency to overlook slightly less environmentally beneficial technologies in favour of the 'Holy Grail' type technologies which seek to be almost perfect from the outset. Two respondents from the petrochemical industry stated that being 'too' strict on the technologies in their early stages was detrimental. They stated that the best opportunity was to develop technologies we know work well today and over time the sustainability will be improved. One respondent, from a major international petrochemical company, justified this suggestion based on experience with palm oil production:

"Biofuel production using Palm oil is the best one because it"s an existing technology that we can scale up now, and we can get the yields up on those, rather than start with new 
technologies that are no good...the sustainability isn't as good today but if we put measures in place it can be."

\section{Lack of supply chain certification}

Although certification was a minor issue in the interviewees, one respondent spoke at length about a potentially overlooked issue surrounding the certification of the supply chains. The respondent, from a certification and testing company, explained that within the EU, aviation biofuel blends cannot be distributed through existing fossil-fuel pipe lines or mixed in with standard jet fuel mixing facilities. This is because of a lack of integration of ASTM with the UK's DEF-STAN and EU's AFQGS. This means that dedicated systems are still required for the fuel, despite it being fully certified in up to 50\% HEFA and FT fuel blends with standard jet fuel. Although the volumes are quite low at present, it was acknowledged by one respondent that this is causing logistical constraints for trials.

\section{CONCLUSION}

This paper has illustrated that the drivers and constraints for aviation biofuels are complex and there is no clear consensus about how to overcome the constraints. Certainly, respondents from all sectors agreed that developments in aviation biofuel are being driven by broad industry needs; namely the need to reduce emissions, the need to reduce vulnerability to oil price rises and exposure to future carbon pricing, energy security and the need to continue using existing engines and infrastructure. The opportunity created by new markets for biofuels was considered to be of lesser importance. However, as well as factors that are driving the development of the fuels, respondents identified a number of constraints that are conspiring to restrict the uptake and commercialisation of aviation biofuels. These constraints include a lack of feedstocks; high costs; low funding; sustainability concerns; a lack of policy incentives and fuel consistency and infrastructure. It is thus not unreasonable to assume that until concerns surrounding cost, sustainability and policy support are addressed, aviation biofuels will not form a significant share of the aviation fuel market.

Almost all the respondents suggested that further scientific research is required into new feedstocks and production technologies that utilise non-edible forms of biomass. The development of newer biofuel technologies is proceeding quickly, however cost and sustainability challenges remain. In the short to medium term it will be necessary for the industry to establish robust sustainability criteria and accounting procedures for aviation biofuels that can be agreed at a global level. In addition, the industry must work with other agencies so that any criteria that are agreed have credibility.

\section{ACKNOWLEDGEMENTS}

We would like to extend our thanks to the two anonymous referees for their very detailed and insightful comments which substantially improved the paper.

\section{REFERENCES}

ASTM Aviation Fuel Standard takes flight - D7566 Revision adds bio derived components, 2011 http://www.astm.org/SNEWS/SO_2011/enright_so11.html

Blakey. S., Rye. L. and Wilson. C. W. Aviation gas turbine alternative fuels: A review. Proceedings of the Combustion Institute 33, 2011, 2863-2885.

Bows-Larkin A and Anderson K (2013) Carbon budgets for aviation or gamble with our future? In Budd L, Griggs S and Howarth D (Eds) Sustainable Aviation Futures Bingley, Emerald, 65-84.

British Airways. Solena- one destination Available online at: www.onedestination.co.uk/environment/climate-change/biofuels/solena [Accessed July 22 2013]. 
Chuck C J O and Donnelly J (2014) The compatibility of potential bioderived fuels with Jet A-1 aviation kerosene Applied Energy, 118(1), 83-91.

Committee on Climate Change. Meeting the aviation target - options for reducing emissions to 2050, 2009. http://www.theccc.org.uk/reports/aviation-report [Accessed May 10 2013].

Corporan, E., Edwards, T. Shafer, L., DeWitt, M.J., Klingshirn, C., Zabarnick, S., West, A., Striebich, R., Graham, J., and Klein, J. Chemical, Thermal Stability, Seal Swell, and Emissions Studies of Alternative Jet Fuels. Energy Fuels, 2011, 25 (3), 955-966.

Enviro.aero Aviation biofuel flight tests, 2012 Available online at: http://www.enviro.aero/Testing-programme.aspx [Accessed $12^{\text {th }}$ May 2013].

FAA (Federal Aviation Administration (2011) FAA Destination 2025 Avaialable on-line at: www.FAA.Gov/about/plans_reports/media/destination2025.pdf.

Florentinus, A. Hamelinck, C. van den Bos, A. Winkel, R. and Cuijpers, M. (2012) Potential of biofuels for shipping Final Report. Ecofys Project number:BIONL11332. http://www.ecofys.com/files/files/ecofys_2012_potential_of_biofuels_in_shipping_02.pdf [Accessed May 12 2013].

Freedman D (2014) Market-driven considerations affecting the prospects of alternative road fuels Philosophical Transactions of the Royal Society A 372(2006), 2-23.

IATA (International Air Transport Association) (2009) A global approach to reducing aviation emissions. Available on-line at www.iata.org.

IATA (International Air Transport Association) (2013) IATA 2013 report on alternative fuels, $8^{\text {th }}$ edition, Available on-line at: www.iata.org/publications/documents/2013-report-alternativefuels.pdf

IEA (International Energy Agency) Bioenergy - A Sustainable and Reliable Energy Source Paris, 2009.

http://www.globalbioenergy.org/bioenergyinfo/background/detail/en/news/29600/icode/ [Accessed May 10 2013].

KLM Sustainable Biofuels - Road to sustainable biofuels. http://www.klm.com/csr/en/climate/footprint/biofuels/index.html, 2012. [Accessed $12^{\text {th }}$ May 2013].

Köhler J, Walz R, Marscheder-Weidermann and Thedieck B (2014) Lead markets in $2^{\text {nd }}$ generation biofuels for aviation: A comparison of Germany, Brazil and the USA Environmental Innovation and Societal Transitions 10, 59-76.

Lane, J. (2013) Fly the (environmentally) friendly skies: Unitied to commence widescale aviation biofuel flights in 2014, Available at: www.biofuelsdigest.com/bdigest/2013/06/05/ Fly-the(environmentally)-friendly-skies:-Unitied-to-commence-widescale-aviation-biofuel-flights-in2014/

Lufthansa (2012) Practical trial of biosynthetic fuel at Lufthansa successful. http://presse.lufthansa.com/en/newsreleases/singleview/archive/2012/january/09/article/2061.html [Accessed 10 ${ }^{\text {th }}$ May 2013].

Naik. S. N, V.V. Goud, Rout. P. K., Dalai. A.K. (2010) Production of first and second generation biofuels: A comprehensive review. Renewable and Sustainable Energy Review 14, $578-597$.

Nair, S. and Paulose, H. (2014) Emergence of green business models: The case of algae biofuel for aviation Energy Policy 65, 175-184. 
Panoutsou C, Bauen A and Duffield J (2013) Policy regimes and funding schemes to support investment for next-generation biofuels in the USA and the EU-27 Biofuels, Bioproducts and Biorefining 7(6), 685-701.

PricewaterhouseCoopers (PWC) (2013) Recovering airline industry on track for profitability in 2013, according to $P w C$ Available online at www.pwc.com/us/en/pressreleases/2013/recovering-airilne-industry-on-track.jhtml 24/06/2013 Accessed 07/03/2014.

Stephenson, D., (2012) Sweet ideas: Options grow for possible power sources of future airplanes, Available on-line at:

www.boeing.com/features/2012/05/corp_innovative_thinking_05_07_12.html

Winchester, N., McConnachie, D., Wollersheim, C., and Waitz, I. (2013a) Economic and emissions impacts of renewable fuel goals for aviation in the USA. Transportation Research Part A: Policy and Practice 58, 116-128.

Winchester, N., McConnachie, D., Wollersheim, C., and Waitz, I., (2013b) Market cost of renewable jet fuel adoption in the United States. A Partner Project 31 Report, Partner MIT. 